\title{
Trying to make Italian scientific research useful
}

\begin{abstract}
$\mathrm{T}^{\mathrm{o}}$ OCHIEVE one's own ministry must be a cherished hope of many a minister without portfolio. Italy's Minister for the Coordination of Scientific and Technological Research has little real power-he does not, for example, appoint the President of the CNR (National Research Council). But Sr Mario Pedini's prophecy rested on the progress of a bill being examined in Parliament for the creation of a Ministry for Scientific Research. And he spoke for many Italians when he argued for more surveillance over research. Along with the general despair over the way that both education and industry are run there has recently arisen the strong feeling that the solution lies in science-that if only academic pursuits could be programmed to the needs of the country all would be well.
\end{abstract}

In a brief history of Italian research written for a permanent commission of the Senate, A. Alberigi Quaranta summarises the attitudes which led to the current state of affairs. Italian science, stifled by the Fascists, got off to a bad start after the war. American generosity was largely to blame for this: it disguised the need for industrial innovation and provided the means for many of the brightest young researchers to emigrate. In the $1960 \mathrm{~s}$, while pure research was flourishing, at least in patches, the state of applied research remained pitiful. This, the argument goes, stemmed partly from the strong inclination of Italian education and culture towards theory as opposed to application, partly from the attitudes of industry, in particular of the many small firms which had not the resources for research or development, and partly from the lack of guidance on the part of the government.

Against all this there is now a violent reaction. Most of the Ministers of Research of the last ten years have in fact supported some project or other for a ministry. But the issue is now a much hotter one. Parliament has been examining two proposals for a ministry: Sir Pedini's bill, recently approved by the late government, and an extra-governmental one supported by parliamentary Christian Democrats, Communists, Socialists and Liberals.

The latter parliamentary text sees the function of the ministry as coordination and political direction of research: these powers, it says, would be withdrawn from the CNR. It pro-

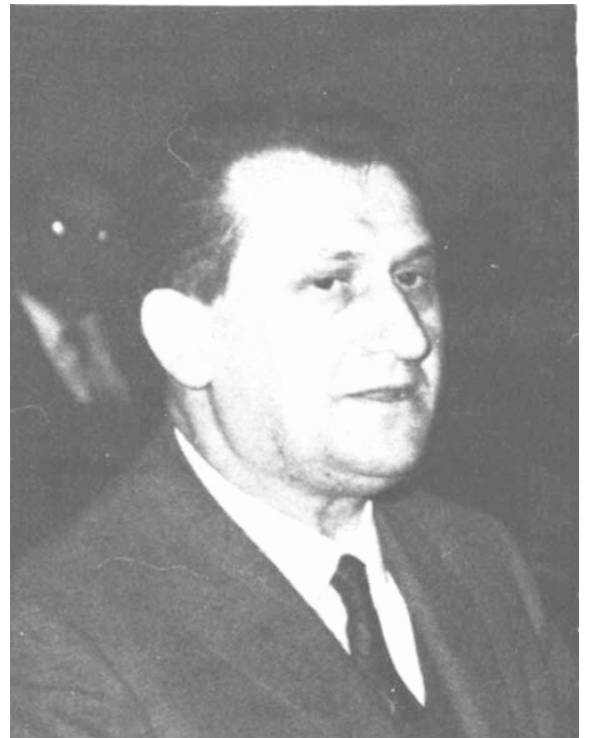

other research. The Minister will report at the end of April on the state of research and the value of the submitted projects, and the Interministerial Committee for Economic Planning (CIPE) will make its final report to the Treasury by May 31 .

Reactions to the proposals in academic circles have been mixed. On the one hand many academics want to do something useful for their country, and they welcome the possibility of an end to their frustration at the lack of contact between universities and the outside world. On the other hand there is the fear, far from unjustified in Italy, that anything the government touches will grind to a halt, stalled by bureaucracy. The new enthusiasm for coordinating everything is also worrying. The universities are hardly mentioned in Pedini's bill. The sums for research they receive at present from the Ministry of Education are negligible. Pure research will clearly be in a very unhappy position if its only source of funds is through a ministry whose purpose is to administer science "in relation to the technical, social and economic progress of the country". Answering a query about his intentions for universities, Pedini has said, "Let's start with the minstry, and when it has reached puberty we'll mate them"-which is hardly reassuring.

Certain obvious questions beg themselves. Why a ministry, when a body already exists which funds and coordinates science, namely the CNR? Why could the CNR not forge the links between research and development, between university and industry? Part of the answer is that the CNR has tried, and failed. A total of 28,000 million lire were spent between 1964 and 1972 on twenty applied research projects; the CNR's own judgment was that most of these were unsatisfactory. Though the scientific merit of the projects was considered carefully when they were planned, there was no proper investigation of whether development would be economically feasible, or even whether there was any Italian industry in a position to use the results. The CNR, in fact, is not equipped to make decisions about conomics and industry: it represents the interests of academics, with 128 of the 140 members of its Scientific Committees academics, and members of these committees also on its Administrative Board. 
But the CNR, undeterred by these drawbacks and alarmed by the prospect of a ministry, is having another go at applied research. In 1972, after consulting researchers and the Office for Economic Development, it put forward 78 proposals for research projects with potential economic or social applications. By the beginning of 1975 an initial selection had reduced the number of projects to about 40 , grouped into seven themes: energy (eg. solar and geothermal energy, conservation of energy); food (eg. increasing plant productivity, new sources of protein, mechanisation of agriculture, fisheries research); health (eg. preventative medicine, viruses, reproduction, biomedical technology); environment (eg. geodynamics, oceanography, soil conservation); educational theory; advanced technology (eg. telecommunications with centimetre and millimetre waves, power lasers, superconductivity, ceramics, control of air traffic); and cognitive advancement (a ragbag including criminology and astrophysics).

These projects, together with assessments of their feasibility and usefulness, were submitted to the CIPE in April 1975. The CIPE's ruling, published on October 9, was startling. The entire 'Health' programme and almost all of 'Food' were approved. 'Energy' and 'Environment' were heavily lopped; nothing remained, for example, of the projects on solar and geothermal energy. 'Cognitive Advancement' and 'Educational Theory' were rejected, at least for the present. But most surprising, after all the trumpeting about the economic needs of the country, 'Advanced Technology' was almost completely rejected: only the project on the control of air traffic remains.

It is possible that the government has simply lost faith in the CNR's ability to know what industry needs, and prefers to wait for the Ministry for Research. This might be deduced from the extremely fuzzy explanations the CIPE report gives for its decisions. Perhaps the CIPE is concerned to prevent toes from being trodden on-the National Electricity Board (ENEL), for example, may consider research into new sources of energy its own preserve. It may also be considering the violent public dislike of multinationals, which could see the research on telecommunications, for example, as somehow pandering to the Americans.

In any case about 20,000 million lire have been set aside for the first year's research on those projects which have survived scrutiny. Owing to administrative delays it will not actually be handed out until towards the end of this year. The CNR's 1975 grant of 83,000 million lire is increased this year to 100,000 million lire, which means 3,000 million lire less for other research of the CNR - a blow at any time but especially with inflation.

Will the success of the applied projects make the loss worthwhile? Unfortunately the answer is likely to be no. The projects suffer from the defect seen in all CNR funding, which is ultimately the fault of the way Italian universities are organised. Substantial amounts of money are divided into too many little sums, with the result that there is much duplication and nobody has the resources for a major piece of work. The practice arises because Italian universities are divided into small faculties, usually with one full professor each, which jealously maintain the barriers between themselves and other faculties. The CNR has naturally never challenged this arrangement, and nothing has changed with the new applied projects: only one quarter of the money is going to CNR institutions, some at least of which are big enough for a more flexible, interdisciplinary approach; most of the rest is destined for hundreds of university faculties.

Given this, and the fact that little thought seems to have been directed at precisely how the results achieved are to be made available to those who might use them, the projects seem likely to cause little more than a ripple in Italian economic or social life. But one thing to be thankful for is that the money is there to do something with. If a large part of it ends up financing the pure research that the academics really want to do, many would say so much the better. But when the Ministry for Research is created, money for pure research may be difficult to come by.

\title{
Getting the message across
}

\author{
David Spurgeon reports from Ottawa on \\ science and the mass media in Canada
}

A STUDY on communication of science through the mass media confirms what Canadian scientists, science writers and ordinary readers have known for a long time: that the Canadian media do an inadequate job of making science meaningful to their public. But, surprisingly to some, it also indicates that a far greater public desire exists for science coverage than most media managers seem to realise.

The study, begun in 1973, was published recently by the Canadian

* Media Impact, Volume 2, Science, Mass Media and the Public, A Research Study on Science Communication. By Orest Dubas and Lisa Martel (Information Canada; June 1975).
Ministry of State for Science and Technology (MOSST)*. It indicates, for example, that science writers are willing and anxious to do a better job, but that they are hindered by the out-dated ideas and prejudices of their bossesthose who control what the media transmit to the public. At the same time, it reveals that much of the general public is just as interested in learning about science as about those other human activities that receive preferential treatment by the media; yet because of the attitudes of the media managers, this desire goes unsatisfied. The study shows how great the need is for better science coverage, for it reveals the abysmal ignorance about Canadian science on the part of those

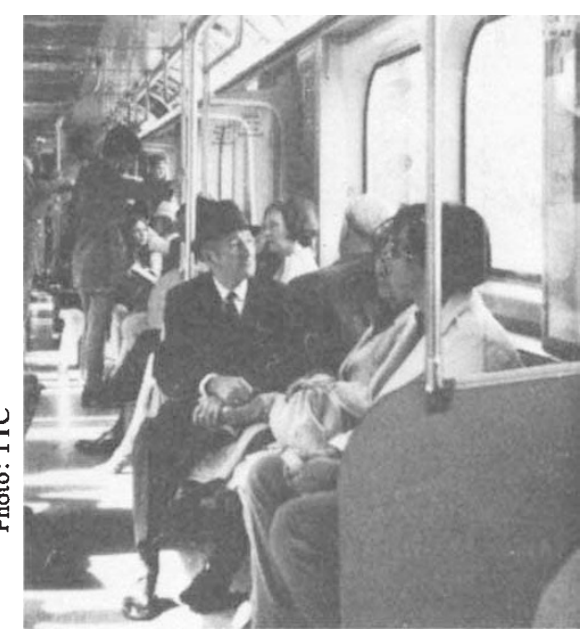

Toronto Transit commuters: does the Canadian public at large get the science coverage it wants?

same members of the public who want to know more.

The results contained in the second volume, released to the public last month, are the outcome of three separate surveys made of managing 